\title{
Proceeding
}

Performance Analysis Workshop, 2 - 5 April 2013, Alicante, Spain

\section{Relationship between performance in game actions and the match result. A study in volleyball training stages.}

\author{
FERNANDO CLAVER RABAZ , RUTH JIMÉNEZ CASTUERA, ALEXANDER GIL ARIAS, ALBERTO \\ MORENO DOMÍGUEZ, M. PERLA MORENO ARROYO
}

Faculty of Sport Sciences, University of Extremadura, Cáceres, Spain

\begin{abstract}
Claver F, Jiménez R, Gil A, Moreno A, Moreno MP. Relationship between performance in game actions and the match result. A study in volleyball training stages. J. Hum. Sport Exerc. Vol. 8, No. Proc3, pp. S651-S659, 2013. In recent years, a number of quantitative methods have been identified and developed with the specific intent of assisting the objective analysis of athletic performance (Nelson \& Groom, 2012). The main aim of this research was to clarify the importance of performance in game actions as determinant of match result in a sample of young volleyball male players. The study sample was composed of 74 male participants belonging to the Under-16 teams (M: 14.61; SD: .88) from the Extremadura Volleyball League in the 2010/2011 season. The studied variables were: performance in game actions (serve, defense, setting and spike) and match result (win/lost). FIVB Observational System (Coleman, 1975) has been the instrument for data recollection, it has been applied previously in numerous studies and is accepted as a valid tool for research community. The T-test for independent samples results showed statistically significant differences in performance of game actions: serve $(F 1,72=3.86 ; p=.048 ; n p 2=.492)$, defense ( $F 1,72=14.07 ; p<.001 . ; n p 2=.959)$, setting (F1,72=34.83; $p<.001$; $n p 2=1.00)$ and spike (F1,72=9.05; $\mathrm{p}=.004 ; \mathrm{np} 2=.84$ ) between players from winner and loser teams. Our results coincide with previous studies that emphasize the importance of game actions in volleyball (Asterios et al., 2009). This analysis is important as it assists in the collection of performance information that can feedback athletes in an attempt to enhance their understanding and competitive performance (Maslovat \& Franks, 2008) and also for talent identification and recruitment (Carling et al., 2005). Key words: PERFORMANCE, MATCH RESULT, VOLLEYBALL, FORMATIVE STAGES.
\end{abstract}

Corresponding author. Faculty of Sport Sciences. University of Extremadura.. Av. de la Universidad s/n, 10071. Cáceres, (Spain).

E-mail: fclaver@unex.es

Performance Analysis Workshop, 2 - 5 April 2013, Alicante, Spain

JOURNAL OF HUMAN SPORT \& EXERCISE ISSN 1988-5202

(c) Faculty of Education. University of Alicante

doi:10.4100/jhse.2013.8.Proc3.11

VOLUME 8 | Proc3 | 2013 | S651 


\section{INTRODUCTION}

In recent years, a number of quantitative methods have been identified and developed with the specific intent of assisting the objective analysis of athletic performance (Nelson \& Groom, 2012). So, has been argued that there is a much greater need for objective and unbiased performance assessment in coaching (Carling et al., 2009; Hughes \& Bartlett, 2008; Maslovat \& Franks, 2008).

In this line, several studies (Hunter \& O'Donoghue, 2001; James et al., 2004, 2005; Vivian et al., 2001) have followed the recommendations of Hughes \& Bartlett (2002) and focused upon the development and utilization of performance indicators (Jones et al., 2008). Few of these studies have attempted to provide indicators of team performance through the comparaison of winner and loser teams in different sports (Hughes \& White, 1997; Hunter \& O'Donoghue, 2001; Jones et al., 2004; McCorry et al., 2001; Stanhope \& Hughes, 1997).

One of the sports that has become most popular on the planet is Volleyball. Worldwide 800 million people participating and playing the game at least once a week (Kenny \& Gregory, 2006). Usually, in volleyball, teams are judged based on their ability to win matches (Luhtanen et al., 2001). Reasons for the successful or unsuccessful outcome of the match depend upon a number of factors (Marcelino et al., 2005). Among these, it is possible to measure indicators of the situation efficacy of elements or phases during the match (Marelić et al., 2005). There are certain characteristic phases that are repeated during a volleyball match, that is, serve, reception of serve, setting, spike, block, and defense (Selinger \& Ackermann-Blount, 1992). These phases determine the skills that each player should possess so as to cope with success with the demands of the match (Katsikadelli et al., 2000; Kollath, 1996).

However, few researches are conducted in relation to the significance of this technical elements contributing to the final outcome of a match, considering service and reception (Ejem, 2001), blocking efficiency and attack (spike) (Coleman, 1992; Lobietti, 2009), spiking and blocking (Palao et al., 2004), service "aces" and counter-attack (Zetou et al., 2007), attack and successful reception of service (Charitonidis et al., 2007) or the quality of the setter (Beal,1993), as predictive factors for winner a match (Asterios et al., 2009).

The main aim of this research was to clarify the importance of performance in game actions as determinant of match result in a sample of young volleyball male players. The following hypothesis has been contemplated in this study: "players of the winner teams will show higher performance values (serve, defense, setting and spike) than players of loser teams".

\section{MATERIAL AND METHODS}

\section{Participants}

The study sample was comprised of 74 male players, aged between 12 and 16 (M: 14.61; SD: .88). Participants belonged the 8 volleyball teams from a top-level Spanish regional league. The study took place during the 2010/2011 season. The protocol was fully approved by the Research Ethics Committee of the University of Extremadura (Spain). All players and their parents or guardians were fully informed about the study, and they signed a consent form. 


\section{Measures}

The dependent variable considered in our study was the match result, distinguishing between winner and loser teams.

The following independent variables were considered in the study: serve effectiveness, defense effectiveness, setting effectiveness and spike effectiveness, defined as the performance or effect obtained with the serve, defense, setting and spike. In order to assess the effectiveness, the FIVB statistics system, was used. The FIVB statistical system was designed by the International Coach Commission of the Fédération Internationale de Volleyball in 1979 (Díaz, 1992) and adapted from Coleman et al. (1969) and Shall's Statistic System (Coleman, 1975). It distinguishes different levels of performance in the different game actions. So, it is accepted as a valid tool for research community and has been applied previously in numerous studies.

The five levels distinguished to categorize serve performance were: a) Error (0): failed action or action that did not allow for continuity (point for the opponent); b) Maximum opponent attack options (1): action was easily passed and allowed the opponent to attack; c) Limited attack options for the opponent (2): action was passed and opponent attacked with some attack options; d) No opponent attack options (3): action was passed but opponent could not attack (they simply passed the ball); and e) Point (4):ace (López- Martinez \& Palao, 2009).

Performance of defense efficacy was assessed as follows: a) Error (0): error, b) Average (1): no attack options, c) Good (2): limited attack options d) Very good (3): maximum team attack options (Palao et al., 2009).

Assessment of performance in set was based on a 5-point numerical rating scale, which quantifies the efficacy of skill performance within a range of performance scores from 0 to 4 a) Average (1): a set that forced the attacker to give an easy or down ball, or a free ball to the opposition regardless of the condition of the opposing block; b) Good (2): a set that allowed the opponent blockers to set up a solid block against the attacker; c) Very good (3): an accurate set and an incomplete two-man block, or moderate set and oneman or incomplete two-man block; and d) Excellent (4): an accurate set that puts the attacker against a one-man opposing block or no block at all. The incomplete block refers to the situation where one of the blockers jumped in the wrong spot or was late to set up a solid double block against the attacker. Moderate set is defined as a high or medium or quick set in relation to the attacker in terms of height, trajectory, place and distance from the net (Bergeles \& Nikolaidou, 2011).

Performance of attack efficacy was assessed as follows: a) Error (0): the attacker made a mistake resulting in a lost point or side-out; b) average (1): the attacker attacked with a down ball or easy ball or free ball, providing an advantageous situation for the opponent team; c) Good (2): the attacker attempted to kill but the spike was quality of the dig; d) Very good (score 3): the attacker attacked in such a way that his team could repeat the attack and, e) excellent (4): the attacker gets a point or achieves a side-out (Bergeles \& Nikolaidou, 2011).

With the categories of performance in that four game actions, an efficacy coefficient was calculated (sum of the attempts per category multiplied by the value of the category and divided by the total attempts (Coleman, 1975)). 


\section{Procedures}

The matches were recorded using a SONY HDR-XR155 digital camera on M2TS format. This camera was located at one of the ends of the court, guaranteeing a height of $5 \mathrm{~m}$ above floor level, to obtain an optimal line of sight.

The aforementioned variables were measured via the systematic observation of the game actions. After collecting the data, all the matches were observed by one single observer. To guarantee the reliability of the observation, one observer, with experience in this function and with good knowledge of volleyball, carried out a training process using, in the different training sessions, samples with different characteristics (category, gender, position in the classification), and exceeding $10 \%$ of the total sample, indicated by Tabachnick \& Fidell (2007). The intraobserver Cohen's Kappa values reached, in the observation of all the variables, were higher than .81, which was the minimum value considered to be almost perfect agreement (Landis \& Koch, 1977). To guarantee the time reliability of the measurement, the same coding was developed on two occasions, with a time difference of 10 days, obtaining Cohen's Kappa values of over .81 .

\section{Statistical analysis}

The descriptive analysis and a T-test for independent samples was performed to check the differences between winners and losers in the studied variables (table 1).

\section{RESULTS}

Table 1. Descriptive and inferential analysis for match result as dependent variable

\begin{tabular}{lllllll} 
& $\mathrm{N}$ & Media & $\mathrm{DT}$ & $\mathrm{F}(1,72)$ & $\mathrm{Np}$ & $\mathrm{p}$ \\
\hline $\begin{array}{l}\text { Serve } \\
\text { effectiveness }\end{array}$ & Winners & 2.09 & .82 & 3.86 & .492 & .48 \\
\cline { 2 - 4 } & Losers & 1.73 & .64 & & & \\
\hline $\begin{array}{l}\text { Defense } \\
\text { effectiveness }\end{array}$ & Winners & 2.25 & .80 & 14.07 & .959 & $<.001$ \\
\cline { 2 - 4 } & Losers & 1.55 & .73 & & & \\
\hline $\begin{array}{l}\text { Setting } \\
\text { effectiveness }\end{array}$ & Winners & 2.84 & .19 & 34.83 & 1.00 & $<.001$ \\
\cline { 2 - 5 } & Losers & 2.21 & .66 & & & \\
\hline $\begin{array}{l}\text { Spike } \\
\text { effectiveness. }\end{array}$ & Winners & 2.50 & .83 & 9.05 & .84 & .04 \\
\cline { 2 - 5 } & Losers & 1.96 & .59 & & & \\
\hline
\end{tabular}

The descriptive analysis showed that "players of the winner teams will show higher performance values (in the actions of serve, defense, setting and spiking) than players of loser teams".

By the $\mathrm{T}$ - test to compare independent samples we observed significant differences between players from winners and losers teams in the variables: serve effectiveness, defense effectiveness, setting effectiveness and spike effectiveness. 


\section{DISCUSSION AND CONCLUSIONS}

The main aim of this research was to clarify the importance of performance in game actions as determinant of match result in a sample of young volleyball male players.

The following hypothesis has been contemplated in this study: "Players of the winner teams will show higher performance values (serve, defense, setting and spike) than players of loser teams". Our results allow us to verify this hypothesis and coincide with previous studies that emphasize the importance of game actions in volleyball (Asterios et al., 2009).

Acording to Marcelino et al. (2005), in volleyball, the action which exhibits the strongest correlation with victory is the spike (Palao et al., 2004; Häyrinen, 2004) followed by the serve (Fernandes \& Moutinho, 1996), and, lastly, the block (Oliveira et al., 2005) as the three final actions.

Regarding to the action of serve, just like attacking and blocking, it has a purpose-determined nature and may be decisive in a team's performance (Asterios et al., 2009; Drikos et al., 2009). The benefit of the serve is not just that a point is immediately scored, but rather, the serve has an influence on the later development of the game. Thus, it has been observed that the execution of a good serve (power serve or with a tactical intention), affects the reception performance (Quiroga et al., 2010, 2012; Ureña et al., 2002) and the attacking options of the opposite team, reducing first tempo attacks and increasing second tempo attacks (Papadimitriou et al., 2004; Palao et al., 2009; Eom \& Schutz, 1992). This influence of the serve on the attack options causes an increase in blocking performance, significantly increasing triple block (Palao et al., 2004), which would facilitate the defence.

Due to the importance of the serve in the development of the game, many different research studies have been developed to determine the typical characteristics of the serve and how this affects the opposite team, both at a high level and in formative stages.

Regarding to the action of defense, although the final actions are most relevant to the performance of a team (Moreno et al., 2005), all previous actions influence the final action. In this sense, the study of Hughes \& Daniel (2003) determines that the quality of attack depends on the quality of the setting, which depends on the quality of defense or reception. Miskin et al. (2010), in a study with a first division team, verified that the defense and the setting assumed extreme importance on the results of this team. According to Palao et al. (2006), the spike effectiveness is decisive in the game but the defensive action assumes a role of fundamental importance for competitive success. We can say then, that the attack captures the attention of the public, but defense wins matches and championships (Lyskevich \& Neville, 1992). Monteiro et al. (2009) analyzed the relationship between the result of the set and the effectiveness of the defense and the attack on the elite men's volleyball, finding a significant relationship between both. In the same vein, the study results from Marcelino Mesquita et al. (2010) showed that teams that win the set obtained superior performance in defense.

Regarding to the action of setting, the setter is considered the leader of the attack phase (Mesquita \& Graça, 2002). According to Papadimitriou et al. (2004), the setter is the "key-player" in a volleyball team. They are the one to make contact with the ball 1/3 of the times and greatly affect the team's performance. In particular, they should be in a position to make the right, "clever" sets to the attackers regardless of the area of the court where they stand (Mills, 1997). Even when they receive a bad set, they should turn it to an 
effective attack (Endicott, 1997). Nishijima et al. (1987) found that, for the achievement of victory, the setting pass and the attack are the most important skills.

Regarding to the action of spike, out of all the finalists actions, the attack is the game action from which a team will get more points in competition, showing a strong correlation with the victory and becoming in the largest indicator of success in volleyball (Asterios et al., 2009; Drikos et al., 2009). This is why so many researchers have deepen into the analysis of the attack, conducting studies in order to determine the characteristics of this technical-tactic action. In the same way, they tried to relate the effectiveness of the attack to different variables (front zone, attack, attack direction and type of attack).

In the development of a play, the final actions are the ones that determine the performance of a team, but there are a number of intermediate actions that favor the sequence of play and through which it is possible to achieve a direct point (defense, reception, setting...) (Moreno et al., 2005). In volleyball, points can be achieved only from terminals or finalists actions such as the attack, the setting and blocking, but all previous actions influence the final action and, therefore, the outcome of the match.

The analysis of the game actions is important as it assists in the collection of performance information that can be feedback to athletes in an attempt to enhance their understanding and competitive performance (Maslovat \& Franks, 2008). It also could serve for the purpose of talent identification and recruitment (Carling et al., 2005).

\section{REFERENCES}

1. ASTERIOS P, KOSTANTINOS C, ATHANASIOS M, DIMITRIOS K. Comparison of technical skills effectiveness of men's National Volleyball teams. International Journal of Performance Analysis of Sport. 2009; 9(1):1-7.

2. CARLING C, REILLY T, WILLIAMS MA. Performance assessment for field sports. London: Routledge. 2009.

3. CARLING C, WILLIAMS MA, REILLY T. Handbook of soccer match analysis. London: Routledge. 2005.

4. CHARITONIDIS K, PATSIAOURAS A, CHARITONIDI M. Comparison terms of the effectiveness of technical skills between the Greek national volleyball team and other European national teams. Inquiries in Sport \& Physical Education. 2007; 5(3):431-436.

5. COLEMAN JE, NEVILLE B, GORDON B. A statistical system for volleyball and its use in Chicago Women's Assn. International Volleyball Review. 1969; 17:72-73.

6. COLEMAN JE. Some new thoughts about the evaluation of blocking. Coaching Volleyball Special edition. 1992; 10-12.

7. COLEMAN JE. A statiscal evaluation of selected volleyball techniques at the 1974 World's Volleyball Championships. USA: Brigham Young University. 1975.

8. DÍAZ J. Voleibol. La dirección de equipo. Sevilla: Edit. Wanceulen. 1992.

9. DRIKOS S, KOUNTOURIS P, LAIOS A, LAIOS Y. Correlates of Team Performance in Volleyball. International Journal of Performance Analysis in Sport. 2009; 9(2):149-156.

10. EJEM M. Brief technical evaluation of the 27th Olympiad in Sydney. The Coach. 2001; 1:6-12.

11. ENDICOTT L. Six secret weapons for setters. Volleyball Magazine, 1997: 54-58.

12. EOM HJ, SCHUTZ RW. Statistical analyses of volleyball team performance. Res Q Exercise Sport. 1992; 63(1):11-18. 
13. FERNANDES S, MOUTINHO C. A importância relativa da eficiência dos proc de jogo na prestação competitiva de uma equipa de voleibol de rendimento. In: Moutinho C, Pinto D. (Eds.). Estudos CEJD 1. Porto: FCDEF-UP. 1996. Pp. 72-77.

14. HÄYRINEN M. Differences between winner and loser teams in men's European top-level volleyball. In: O'Donoghue P, Hughes M. (Eds.). Performance Analysis of Sport VI. Cardiff: UWIC. 2004. Pp. 194-199.

15. HUGHES M, BARTLETT B. What is performance analysis? In: Hughes M, Franks I. (Eds). The essentials of performance analysis: an introduction. London: Routledge. 2008. Pp. 8-20.

16. HUGHES M, DANIEL R. Playing patterns of elite and non-elite volleyball. International Journal of Performance Analysis in Sport. 2003; 3(1):50-56.

17. HUGHES M, BARTLETT RM. The use of performance indicators in performance analysis. $J$ sport sci. 2002; 20(10):739-54.

18. HUGHES MD, WHITE P. An analysis of forward play in the 1991 rugby union world cup for men. In: Hughes MD. (Ed.). Notational analysis of sport I \& II. Cardiff: UWIC. 1997. Pp. 183-191.

19. HUNTER $P$, O'DONOGHUE P. A match analysis of the 1999 rugby union world cup. In: Hughes MD, Franks I. (Eds.). Pass.com: Fifth World Congress of Performance Analysis of Sport. Cardiff: UWIC. 2001. Pp. 85-90.

20. JAMES N, MELLALIEU SD, JONES NMP. The development of position-specific performance indicators in professional rugby union. J Sport Sci. 2005; 23(1):63-72.

21. JONES NM, JAMES N, MELLALIEU SD. An objective method for depicting team performance in elite professional rugby union. J Sport Sci. 2008; 26(7):691-700.

22. JONES NM, MELLALIEU SD, JAMES N. Team performance indicators in rugby union as a function of winner and loser. International Journal of Performance Analysis in Sport. 2004; 4:61-71.

23. KATSIKADELLI A, AGGELONIDIS I, KOUNTOURIS P, LAIOS I. Volleyball Vol. I. Athens: Authors. 2000.

24. KENNY B, GREGORY C. Volleyball: Steps to success. Campaign, IL: Human Kinetics. 2006.

25. KOLLATH E. Bewegungsanalyse in den Sportspielen. Köln, Germany: Sport \& Buch Strauß. 1996.

26. LANDIS J, KOCH G. The measurement of observer agreement for categorical data. Biometrics. 1977; 33(1):159-174.

27. LISKEVYCH T. Dominating Defensive Systems. In: Shondell D, Reynaud C. (Eds.) The Volleyball Coaching Bible. Champaign, IL.: Human Kinetics. 2002. Pp. 282-299.

28. LOBIETTI R. A review of blocking in volleyball: from the notational analysis to biomechanics. Journal of Human Sport and Exercise. 2009; 4(2):93-99.

29. LÓPEZ-MARTINEZ AB, PALAO JM. Effect of Serve Execution on Serve Efficacy in Men's and Women's Beach Volleyball. International Journal of Applied Sports Sciences. 2009; 21(1):1-16.

30. LUHTANEN P, BELINSKIJ A, HÄYRINEN M, VÄNTTINEN T. A comparative tournament analysis between the Euro 1996 and 2000 in soccer. International Journal of Performance Analysis in Sport. 2001; 1(1):74-82.

31. MARCELINO R, MESQUITA I, AFONSO J. The weight of terminal actions in Volleyball. Contributions of the spike, serve and block for the teams rankings in the World League 2005. International Journal of Performance Analysis in Sport. 2005; 88(2):1-7.

32. MARCELINO R, MESQUITA I, SAMPAIO J, MORAES C. Estudo dos indicadores de rendimento em voleibol em função do resultado do set. Revista Brasileira de Educação Física e Esporte. 2010; 24(1):69-78.

33. MARELIĆ N, REŠETAR T, ZADRAŽNIK M, ĐURKOVIĆ T. Modelling of situation parameters in top level volleyball. In: Milanovic D, Prot F. (Eds.). 4th International Scientific Conference on Kinesiology. Zagreb: Faculty of Kinesiology. 2005. 
34. MASLOVAT D, FRANKS I. The need for feedback. In: Hughes M, Franks I. (Eds). The essentials of performance analysis: an introduction. London: Routledge. 2008. Pp. 1-7.

35. MCCORRY M, SAUNDERS ED, O'DONOGHUE PG, MURPHY MH. A match analysis of the knockout stages of the 1995 rugby union World Cup. In: Hughes MD. (Ed.). Notational analysis of sport III. Cardiff: UWIC. 2001. Pp. 230-239.

36. MILLS BD. Volleyball keys to Success: a beginning skills guide. Dubuque, Lowa: Eddie Bowers Pub. 1997.

37. MISKIN M, FELLINGHAM G, FLORENCE L. Skill Importance in Women's Volleyball. Journal of Quantitative Analysis in Sports. 2010; 6(2):1-14.

38. MONTEIRO R, MESQUITA I, MARCELINO R. Relationship between the set outcome and the dig and attack efficacy in elite male Volleyball game. International Journal of Performance Analysis of Sport. 2009; 9(3):294-305.

39. MORENO A, MORENO MP, JULIÁN J, DEL VILLAR F. Estudio de la relación entre la eficacia de las acciones de primer contacto y la eficacia del ataque en voleibol masculino de alto nivel. Kronos. 2005; 8(4):57-61.

40. NELSON L, GROOM R. The analysis of athletic performance: Some practical and philosophical considerations. Sport Educ Soc. 2012; 17(5):687-701.

41. NIKOS B, ELISSAVET NM. Setter's performance and attack tempo as determinants of attack efficacy in Olympic-level male volleyball teams. International Journal of Performance Analysis in Sport. 2011; 11(3):535-544.

42. NISHIJIMA T, OHSAWA S, MATSUURA Y. The relationship between the game performance and group skill in volleyball. International Journal of Physical Education. 1987; 24(4):20-26.

43. OLIVEIRA R. Caracterização da eficácia do ataque, bloco e serviço no voleibol de elevado rendimento competitivo. IV Seminário de Iniciação à Investigação Cientifica. FCDEF-UP. 2005.

44. PALAO J, MANZANARES P, ORTEGA E. Techniques used and efficacy of volleyball skills in relation to gender. International Journal of Performance Analysis in Sport. 2009; 9(2):281-293.

45. PALAO JM, SANTOS JA, UREÑA A. (2004). Effect of team level on performance in volleyball. International Journal of Performance Analysis in Sport. 2004; 4(2):50-60.

46. PAPADIMITRIOU K, PASHALI E, SERMAKI I, MELLAS S, PAPAS M. The effect of the opponents serve on the offensive actions of Greek setters in Volleyball games. International Journal of Performance Analysis in Sport. 2004; 4(1):23-33.

47. QUIROGA M, RODRIGUEZ-RUIZ D, SARMIENTO S, MUCHAGA L, GRIGOLETTO M, GARCIAMANSO J. Characterisation of the Main Playing Variables Affecting the Service in High-Level Women's Volleyball. Journal of Quantitative Analysis in Sports. 2012; 8(1):1-11.

48. QUIROGA ME, GARCÍA-MANSO JM, RODRÍGUEZ-RUIZZ D, SARMIENTO S, DE SAA Y, MORENO MP. Relation between in-game role and service characteristics in elite women's volleyball. J Strength Cond Res. 2010; 24(9):2316-2322.

49. SELINGER A, ACKERMANN-BLOUNT J. Power volleyball. Paris: Vigot. 1992.

50. STANHOPE J, HUGHES MD. An analysis of scoring in the 1991 rugby union World Cup. In: Hughes MD. (Ed.). Notational analysis of sport III. Cardiff: UWIC. 1997. Pp. 167-176.

51. TABACHNICK BG, FIDELL LS. Using multivariate statistics (5th ed.). New York, NY: Pearson Education Inc. 2007.

52. UREÑA A, CALVO R, LOZANO C. Estudio de la recepción del saque en el Voleibol masculino español de élite tras la incorporación del jugador líbero. Revista internacional de ciencias de la actividad física y el deporte. 2002; 2(4):2-11.

53. VIVIAN R, MULLEN R, HUGHES MD. Performance profiles at league, European Cup and International levels of male rugby union players, with specific reference to flankers, number 8 s and 
number 9s. In: Hughes MD, Franks I. (Eds.). Pass.com: Fifth World Congress of Performance Analysis of Sport. Cardiff: UWIC. 2001. Pp. 137-143.

54. ZETOU E, MOUSTAKIDIS A, TSIGILIS N, KOMNINAKIDOU A. Does Effectiveness of Skill in Complex I Predict Win in Men's Olympic Volleyball Games? Journal of Quantitative Analysis in Sports. 2007; 3(4):1-11. 